\title{
Ectopic Perforated Appendicitis in Supraumbilical Region in a Case of Incomplete Intestinal Rotation
}

\author{
Bhimarao ${ }^{1}$, Rashmi Mysore Nagaraju², Lingaraj B. Patil ${ }^{3}$ \\ 1,2 Department of Radiology, Lifeline Hospital, Sohar, Sultanate of Oman. \\ ${ }^{3}$ Department of General Surgery, Lifeline Hospital, Sohar, Sultanate of Oman.
}

\section{INTRODUCTION}

Acute appendicitis is one of the most common causes of acute abdominal pain and the most common condition requiring emergency surgery. Intestinal malrotation is a relatively uncommon condition. Depending upon the location of the cecum and appendix, patients with acute appendicitis in intestinal malrotation present atypically with abdominal pain localized on the site of appendicitis. Due to atypical presentation of central abdominal pain, other differentials presenting in this region should be excluded and accurate diagnosis should be made.

We present a patient who came with central abdominal pain with elevated markers of inflammation. Contrast enhanced CT of abdomen in this patient revealed ectopic appendicitis located in supraumbilical region with signs of incomplete rotation of the bowel. CT played a pivotal role in identifying the underlying rotational abnormality of bowel, in localizing the inflamed appendix, identifying complications (perforation) and excluding other possible intra-abdominal pathologies. It was also helpful in surgical planning. Emergency laparotomy with appendectomy and lavage were performed on this patient who subsequently recovered.

\section{PRESENTATION OF CASE}

A 27-year male presented with severe central abdominal pain and persistent vomiting, associated with mild fever for 2 days. No past medical history of note. On examination, the patient was unwell, in pain, afebrile and hemodynamically stable. His abdomen was distended with diffuse tenderness and guarding, more so in the peri umbilical region. Bowel sounds were sluggish. Routine lab investigations revealed elevated C-reactive protein \& total leucocyte counts and normal amylase levels.

Erect chest radiograph revealed prominent transverse colonic loop in upper central abdomen; no evidence of pneumoperitoneum (Figure 1). Abdominal ultrasound revealed few fluid-filled mild dilated bowel loops in central abdomen showing to \& fro peristalsis (Figure 2), mild free fluid in abdomen with internal echoes and diffuse probe tenderness in abdomen.
Corresponding Author: Dr. Rashmi Mysore Nagaraju, Department of Radiology, Lifeline Hospital, Sohar, Sultanate of Oman.

E-mail: rashmi83nagaraj@gmail.com

DOI: $10.14260 / j e m d s / 2021 / 516$

How to Cite This Article:

Bhimarao, Nagaraju RM, Patil LB, et al. Ectopic perforated appendicitis in supraumbilical region in a case of incomplete intestinal rotation. J Evolution Med Dent Sci 2021;10(31):2521-2524, DOI: 10.14260/jemds/2021/516

Submission 25-03-2021,

Peer Review 01-06-2021

Acceptance 08-06-2021,

Published 02-08-2021.

Copyright $\left({ }_{0} 2021\right.$ Bhimarao et al. This is an open access article distributed under Creative Commons Attribution License [Attribution 4.0 International (CC BY 4.0)] 


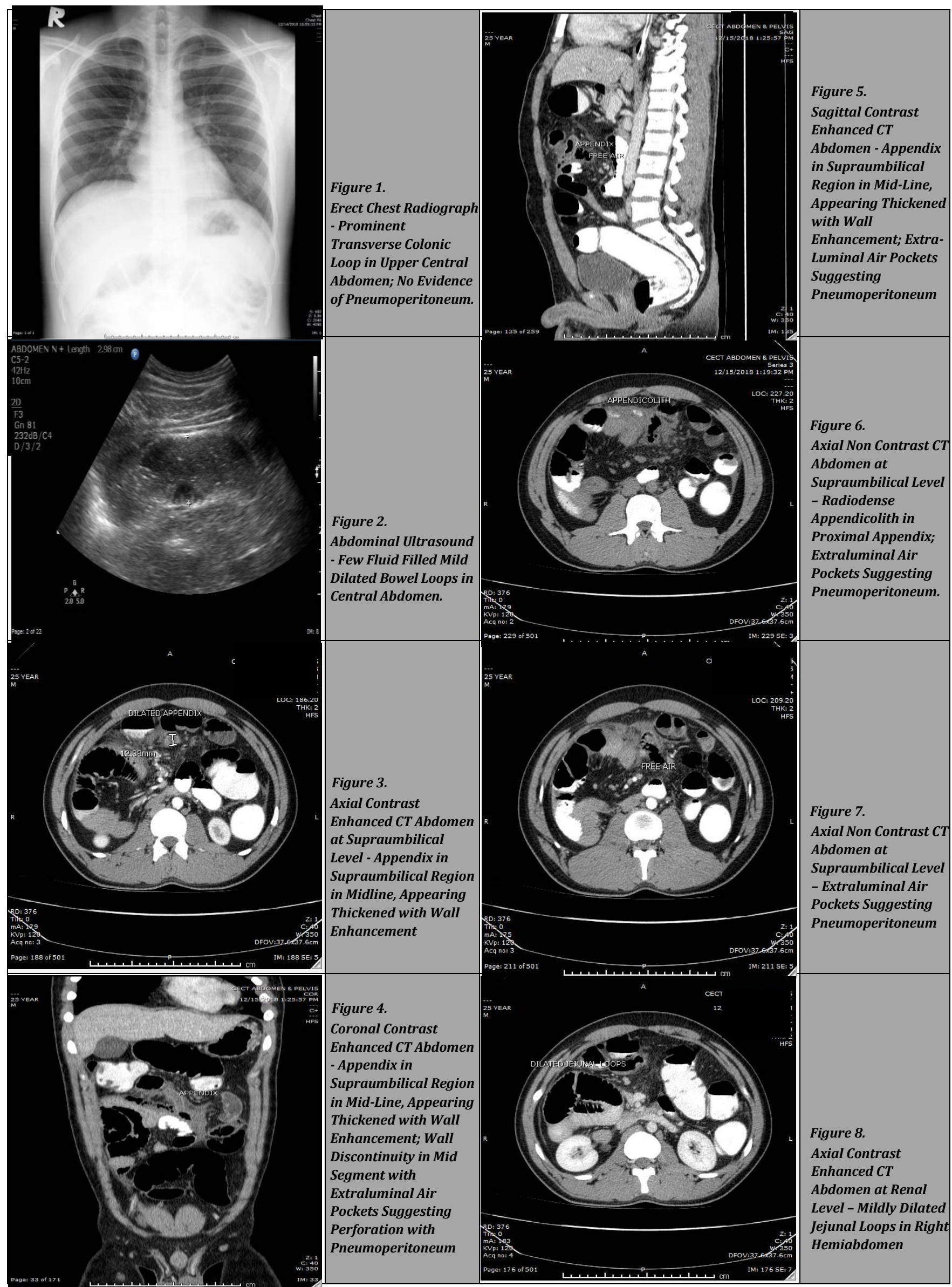




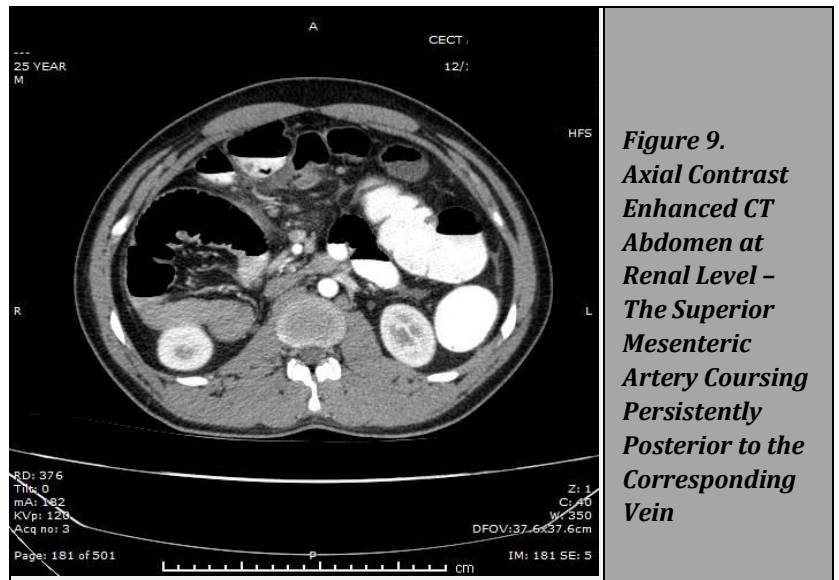

Contrast CT abdomen was performed with oral and rectal contrast to look for the source of intra-abdominal infection, which revealed

- $\quad$ Appendix in supraumbilical region in midline, appearing thickened with wall enhancement (measuring up to 14 $\mathrm{mm}$ in maximum diameter) (Figures 3, 4 and 5). Ovoid radiodense appendicolith $(12 \times 4 \mathrm{~mm})$ in proximal aspect (Figure 6). Presence of wall discontinuity in its mid segment with multiple extraluminal air pockets, suggestive of perforation (Figure 7). Adjacent inflammatory mass formation (measuring $\sim 5 \times 8.5 \times 7$ $\mathrm{cm}$ ) with minimally dispersed fluid, mesenteric fat stranding, lymph nodes (largest measuring $11 \times 7 \mathrm{~mm}$ ) and few adherent bowel loops. Minimal to mild dispersed free fluid in peritoneal cavity.

- Transversely oriented cecum (Figure 4), located in supraumbilical region, to right of midline. Appendicular base at the level of $\mathrm{L} 2$ vertebral body. The hepatic flexure located normally after which the ascending colon was coursing medially with the cecum located in supraumbilical region. Rest of the colonic loops were normally located. Multiple mildly dilated jejunal loops were in right hemiabdomen (Figure 8). Normal caliber ileal loops in left hemiabdomen. The third \& fourth parts of duodenum and the duodeno-jejunal flexure coursing inferiorly in midline. The superior mesenteric artery coursing persistently posterior to the corresponding vein (Figure 9). Findings were in favour of incomplete intestinal rotation.

With the above image findings, diagnosis of perforated appendicitis with appendicolith and inflammatory mass formation in supraumbilical region in a case of incomplete intestinal rotation was made.

\section{DISCUSSION OF MANAGEMENT}

The patient underwent emergency laparotomy which confirmed the radiological diagnosis. Appendectomy (Figures 10 and 11) \& lavage were performed, and abdominal drains were kept. He was allowed oral fluids after 6 days and semisolids after 8 days, which he tolerated. The drains were removed on $9^{\text {th }}$ day and the patient was discharged.

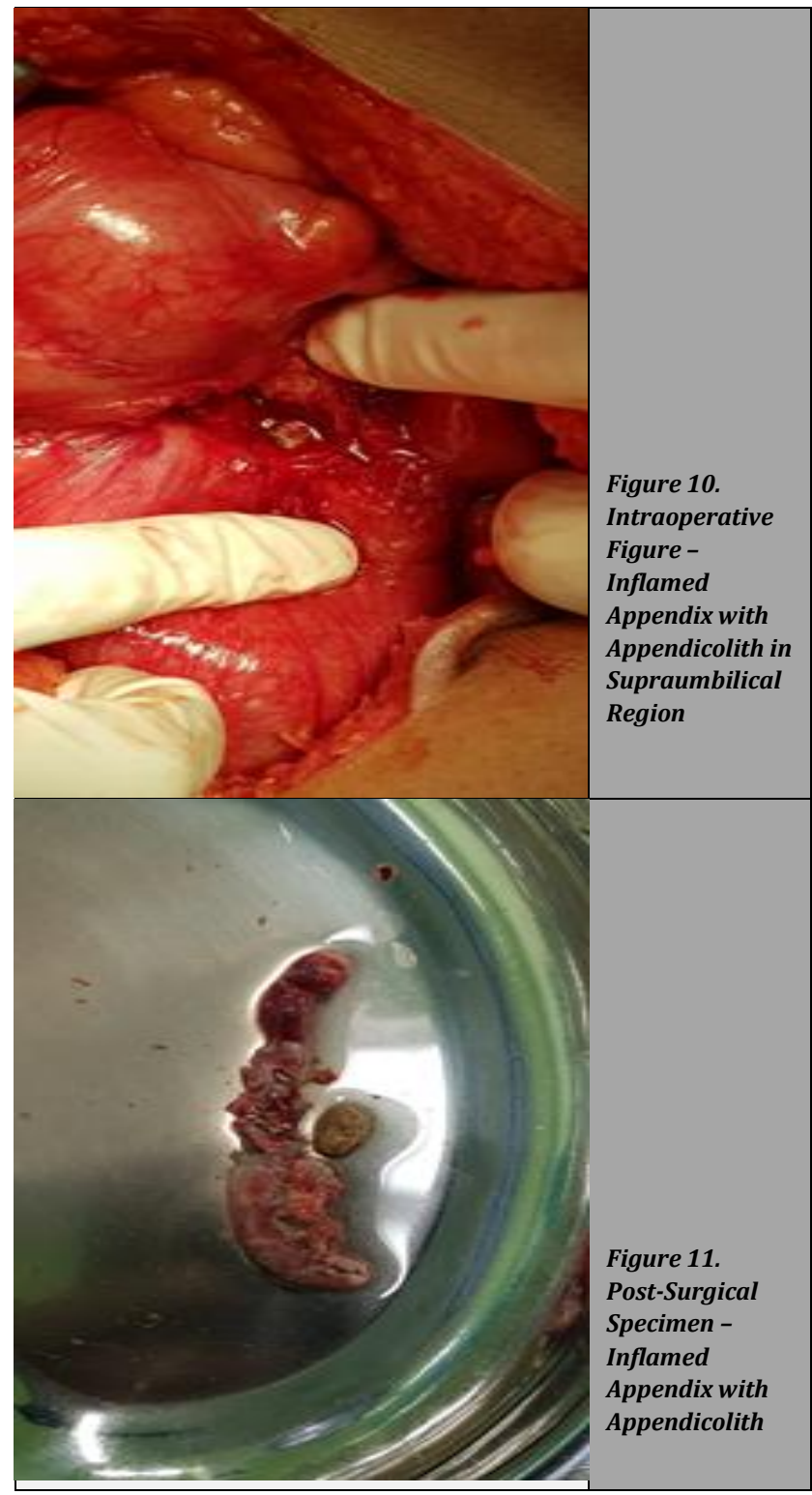

\section{DISCUSSION}

Acute appendicitis is one of the most common causes of acute abdominal pain and the most common condition requiring emergency surgery. It occurs secondary to appendicular luminal obstruction causing fluid accumulation, distension, inflammation and finally in undiagnosed, perforation. ${ }^{1,2}$ The case fatality rate increases from $<1 \%$ to $>5 \%$ with perforation.

It classically presents with abdominal pain (initially periumbilical, later localized to right iliac fossa), fever and vomiting in most patients. However, in about a third of patients the presentation may be atypical. ${ }^{4}$

The diagnosis is based on clinical \& laboratory findings supported by radiological investigations. Ultrasound is noninvasive, rapid, widely available, relatively inexpensive, and non - ionizing and is the first line of investigation. However, it is particularly challenging in large and overweight adults. ${ }^{5} \mathrm{On}$ ultrasound, appendicitis is diagnosed if the outer appendiceal diameter measures $6 \mathrm{~mm}$ or greater in cross section with periappendiceal inflammatory fat changes. With perforation, 
there is loculated pericecal fluid, phlegmon or abscess formation. ${ }^{6} \mathrm{CT}$ is more precise and reproducible with better diagnostic accuracy of $93-98 \%{ }^{3,7}$ CT is better than ultrasound in revealing a normal appendix. An inflamed appendix on CT scan is larger than $6 \mathrm{~mm}$ in diameter and has appendiceal wall thickening and enhancement after contrast media infusion. CT scans also reveal periappendiceal inflammatory changes, including inflammatory fat stranding, phlegmon, free fluid, free air bubbles, abscess, and adenopathy. ${ }^{8}$ Disadvantages of CT include possible iodinated contrast-media allergy, patient discomfort from administration of contrast media, exposure to ionizing radiation and cost.

Intestinal malrotation is a relatively uncommon condition. It occurs secondary to errors of rotation of the midgut about the superior mesenteric artery during weeks $5-10$ of foetal life and subsequent abnormal fixation to the peritoneal wall. Up to $60 \%$ of patients with intestinal malrotation present in the first month of life and another $20 \%$ present between 1 and 12 months, classically with bilious vomiting.

Lesser (incomplete) degrees of intestinal malrotation may present in adult life ${ }^{9}$ which may be incidentally detected or may present with acute bowel ischemia or bowel obstruction secondary to volvulus or with chronic abdominal pain. ${ }^{10}$ Treatment of such incidentally discovered malrotation in asymptomatic patients older than $1-2$ years of age remains somewhat controversial. ${ }^{11}$

Depending upon the location of the cecum and appendix, patients with acute appendicitis in intestinal malrotation may present atypically with abdominal pain localized on the site of appendicitis. In the present case, incomplete rotation of the bowel was incidentally discovered in a previously asymptomatic adult patient, who presented with central abdominal pain secondary to ectopically located acute appendicitis.

Due to atypical presentation of central abdominal pain, other differentials presenting in this region should be excluded and accurate diagnosis should be made. CT played a pivotal role in identifying the underlying rotational abnormality of bowel, in localizing the inflamed appendix, identifying complications (perforation) and excluding other possible intra-abdominal pathologies. It was also helpful in surgical planning. Ultimately, diagnostic laparotomy and laparoscopy may be very useful both in establishing the differential diagnosis in doubtful cases and in performing the definitive surgery. ${ }^{12}$

\section{CONCLUSIONS}

The occurrence of a common pathology like acute appendicitis, in an uncommon pre-existing condition like intestinal malrotation, leads to a diagnostic dilemma. Accurate diagnosis can be achieved by keeping in mind this possibility and with the use of cross sectional imaging modality, especially contrast enhanced CT which provides vital information about the disease process, possible complications and helps in surgical planning. Hence CT must be utilized in such cases to clear the dilemma and start treatment at the earliest, thus saving the patient from a life threatening complication.

Financial or other competing interests: None.

Disclosure forms provided by the authors are available with the full text of this article at jemds.com.

\section{REFERENCES}

[1] Birnbaum BA, Wilson SR. Appendicitis at the millennium. Radiology 2000;215(2):337-48.

[2] Rao PM, Rhea JT, Novelline RA. Helical CT of appendicitis and diverticulitis. Radiol Clin North Am 1999;37(5):895909.

[3] Old JL, Dusing RW, Yap W, et al. Imaging for suspected appendicitis. Am Fam Physician 2005;71(1):71-8.

[4] Lewis FR, Holcroft JW, Boey J, et al. Appendicitis: a critical review of diagnosis and treatment in 1000 cases. Arch Surg 1975;110(5):677-81.

[5] Slovis TL. CT and computed radiography: the pictures are great, but is the radiation dose greater than required? AJR Am J Roentgenol 2002;179(1):39-41.

[6] Kessler N, Cyteval C, Gallix B, et al. Appendicitis: evaluation of sensitivity, specificity and predictive values of US, Doppler US and laboratory findings. Radiology 2004;230(2):472-8.

[7] Perera WR, Hennessy OF. Clinical images. An unusual case of appendicitis. Am J Surg 2010;199(6):e79-e81.

[8] Choi D, Park H, Lee YR, et al. The most useful findings for diagnosing acute appendicitis on contrast-enhanced helical CT. Acta Radiol 2003;44(6):574-82.

[9] Nicholas JM, Rozycki GS. Image of the month. Archives of Surgery 2001;136(6):705-6.

[10] Anjali P, Hatley R. Intestinal malrotation. http://www.emedicine.com/ped/topic1200.htm. WebMD. Accessed: February 25, 2007.

[11] Malek MM, Burd RS. Surgical treatment of malrotation after infancy: a population-based study. J Pediatr Surg 2005;40(1):285-9.

[12] Akbulut S, Ulku A, Senol A, et al. Left-sided appendicitis: review of 95 published cases and a case report. World J Gastroenterol 2010;16(44):5598-602. 